IJEMS: Indonesian Journal of Education and Mathematical Science

2020 Vol. 1, No. 3, pp. 11-18 ISSN(e): 2715-985x

DOI: https://doi.org/10.30596/ijems.v1i3.2602

(C) 2020 IJEMS@UMSU. All Rights Reserved

\title{
EFFORTS TO IMPROVE THE ABILITY TO UNDERSTAND VALUES EDUCATIVE IN MIRRORS THROUGH THE CIRC MODEL (COOPERATIVE INTEGRATED READING AND COMPOSITION) STUDENTS CLASS XI SMA N 1 SUGUNUNG
}

\section{Oleh}

SITI HAZIZAH ANGKAT S.PD

Ppg bahasa Indonesia umsu

\section{ABSTRACT}

Article History

Received: March

2020 Revised: July

2020 Accepted:

ugust 2020

ublished:Septemb

Keywords

blended Learning

Model,

Mathematical

Problem Solving

nLilit.. Initi-l
This Classroom Action Research (CAR) aims to describe (1) the activity student learning during the application of the CIRC learning model, (2) response students towards the application of the CIRC learning model, (3) increasing learning outcomes students to achieve the level of completeness of student learning outcomes in activities understand the educational values in short stories by applying the learning model CIRC, (4) steps taken in implementing the CIRC model. Subject research are the teachers and students of class XI and SMA N 1 SIGUNUNG that numbering 40 people. The object of this research is student learning activities, improvement results, responses and learning steps in applying the model CIRC learning. The data collection method used in this study are the test method, observation method, interview and questionnaire method. Data analyzed using quantitative descriptive and qualitative descriptive techniques. The results of this study were (1) the students were seen to be active in carrying out activities learning, (2) students give very positive responses to application CIRC learning model in short story learning (3) achieving completeness results learn to understand the educational values in students' short stories thanks to the application of the model CIRC learning, namely the pre-action classical average score of 68, cycle I obtained a classical average score of 77, while in the second cycle the classical average score students become 90 and (4) there are several steps for implementing the learning model CIRC to increase activities and achieve mastery learning outcomes understand the educational values in short stories. These steps are emphasized in literature learning, especially short stories that were previously invited to read without intensive understanding it is better to apply the model CIRC which emphasizes students to learn in groups and integrate reading and writing as a reference for understanding literature. Based on the results research, other researchers are advised to apply the CIRC learning model, as an innovative learning model, in other language subjects in general and in Indonesian lessons, in particular. Key words: CIRC learning, understanding ability, educational values 
IJEMS: Indonesian Journal of Education and Mathematical Science

2020 Vol. 1, No. 3, pp. 11-18 ISSN(e): 2715-985x

DOI: https://doi.org/10.30596/ijems.v1i3.2602

(C) 2020 IJEMS@UMSU. All Rights Reserved

\section{A. Introduction}

The curriculum is a set of plans and arrangements regarding objectives, content and lesson materials and methods used as guidelines for carrying out activities learning to achieve educational goals. These goals include goals national education and conformity to the uniqueness, conditions and potential of the region,

education units and students. Therefore, the curriculum is compiled by units education to allow the adaptation of educational programs to needs and the potential that exists in the regions (BSNP, 2006). Development of various Education Unit Level Curriculum (KTSP) refers to national education standards to ensure the achievement of goals national education . National education standards consist of content standards, processes, competence of graduates, educational staff, facilities and infrastructure, management, education financing and assessment. Two of the eight national education standards these, namely Content Standards (SI) and Graduate Competency Standards (SKL) the main reference for educational units in developing curriculum. Literature is a part of Indonesian language subject matter who can pay attention to the socio-cultural characteristics of the local community and maintaining cultural diversity, namely through literary learning. Literature especially short stories inviting students to be sensitive and critical in assessing something intact that happens in everyday life. Moreover, literary learning appears in two ways times in high school level schools, namely in class X semester 1 and class XI semester 2. This shows that short story literature plays a role in creating the existence of critical thinking and sensitivity to students' creativity in understanding, assessing and linking the literary meaning in everyday life. Basically, no literary work is born in a situation, except in it are sparks of a past, middle situation walk, or hope for a culture to come. As well as inside the culture contains positive educational values. It can whether the originators, writers or authors realize it or not. However, in a sooner or later, it will be found by "smart" readers, resulting in educational valuethis is an indication of the existence of a certain culture in a society. On the other hand, this educational value can also affect the next period as a positive foothold in maintaining or creating a new culture much better. This can be seen in various written literary works, such as poetry, short stories, and novels. Educational values are the values of education that are in it includes individual attitudes in personal life, social life, and a life related to God. Various educational value planting through a moral approach carried out in various ways, both formal and non-formal. Literary works can also be used as a means of planting educational values which can be used by readers, because literary works are reflections the problems of life are re-expressed by the author through the characters of the story. Thus, the exploration of educational values of literary works is necessary done considering that the delivery of educational values in literature is not always straightforward straight away. Short story is one of the literary works designated by pengaranag as intermediary reflection of life's problems. Short stories are short stories. However, there are no rules, there is no one agreement between authors and experts. According to Edgar Allan Poe (in Jassin , 1961: 72 ) said that the short story is a story that has been read in Once seated the roughly ranges from half to two hours and that is a thing that would not be done for a novel. Short story is not it only to be read but also need to understand the elements contained in it especially educational values that can affect the level of understanding of readers to its application in real life. Based on preliminary observations and interviews with one of the language teachers Indonesia, Antoni sibarani, S.Pd. at SMA n 1 Sigunung the facts were obtained that the ability to understand the values contained in the short stories in class XI sma $\mathrm{n} 1$ sigunung. Initial data that the authors obtained from learning outcomes short story literature in class XI shows that in following learning literature, most of the students scored below the average KKM it was determined that 72 . Of the 40 students who attended the lesson, only 17 students attended able 
IJEMS: Indonesian Journal of Education and Mathematical Science

2020 Vol. 1, No. 3, pp. 11-18 ISSN(e): 2715-985x

DOI: https://doi.org/10.30596/ijems.v1i3.2602

(C) 2020 IJEMS@UMSU. All Rights Reserved

to get scores above the KKM, while 27 students were not able to reach the predetermined value. Apart from these facts, it is seen from the learning process teaching in class, students seem less active and bored in the classroom. Nothing is get them interested in taking lessons. These things are caused by several factors (1) the methods used in Indonesian language learning, especially literature learning can be said to be less varied and less innovative. The methods commonly used by teachers in Indonesian language learning, especially reading literature is a method of lectures and assignments. (2) Lack of it the use of media in literature learning. Media commonly used in Literature learning is Indonesian language worksheets class XI. (3) Lack of interaction between students and students and between students and teachers. So that it affects their learning outcomes were low and no improvement was seen. Given these problems, there must be a solution just right. To improve the ability to understand educational values in short stories an appropriate, effective and attractive application or learning model is needed . Efforts to optimize literary learning are one form learning to read and write and language skills in high school is using the CIRC model. CIRC learning was developed by Stevans, Madden, Slavin and Farnish. CIRC type cooperative learning in terms of language can be interpreted as a model cooperative learning that integrates a reading as a whole then compose it into important parts. Model This learning is very fun and has been tested in use learning increase student success in learning. The CIRC learning model according to Slavin in Suyitno (2005: 3-4) has eight components. The eight components include: (1). Teams, that is formation of heterogeneous groups consisting of 4 or 5 students; (2). Placement test, for example, obtained from the average of the previous daily test scores or by value report cards so that teachers know the strengths and weaknesses of students in certain fields; (3). Student creative, carry out tasks in a group by creating a situation where an individual's success is determined or influenced by success his group; (4). Team study, namely the stages of learning action that must be carried out by groups and teachers provide assistance to groups who need it; (5). Team scorer and team recognition, namely giving scores on work results group and provide award criteria for successful groups is brilliant and groups that are seen as less successful in resolving task; (6). Teaching group, which provides brief material from the teacher ahead of group assignments; (7). Facts test, namely the implementation of the test ortest based on facts obtained by students; (8). Whole-class units, namely giving summary of the material by the teacher at the end of the lesson with a solving strategy the problem. So far, research on the application of the CIRC model using short story media has not ever done in high school, especially class XI SMA N 1 SIGUNUNG . Research which is closely related to the ability to understand short stories has been done by researchers previous research was conducted by Anton Sibarani (2011) with the title "Application of CIRC Lear ing Model Assisted by Work Cards for Improving Mathematics Problem Solving Ability Grade x in High school 1 skunk ."

\section{B. RESEARCH METHOD}

This study uses a classroom action research design (PTK), because researchers take a new action in order to solve problems and improve the quality of learning in the classroom. Wendra (2007: 45) in his book said that classroom action research is a research conducted in class through certain actions in order to solve the current problem faced by teachers in learning. Actions that researchers take to solving problems consists of several cycles and is carried out in a participatory manner and collaborative. In addition, researchers used a descriptive-quantitative approach and descriptive-qualitative in representing the actions the researcher takes. The research subjects in this study were students of class XI SMA N 1 SIGUNUNG and the subject teacher in the class. The object of this research is the ability to understand educational values in short stories. This research procedure starts from problem analysis. After finding the problem is then carried out reflection. The point of doing the initial reflection is to identify the problems 
IJEMS: Indonesian Journal of Education and Mathematical Science

2020 Vol. 1, No. 3, pp. 11-18 ISSN(e): 2715-985x

DOI: https://doi.org/10.30596/ijems.v1i3.2602

(C) 2020 IJEMS@UMSU. All Rights Reserved

faced by both teachers and students in the learning process. Before the action is implemented, make a plan learning is very necessary. The action plan will become a guidelines in carrying out actions. After creating a plan of action ature, then proceed with the implementation of the action. The implementation of this action must be adjusted to the plans that have been made. After the implementation of the action, followed by reflection on action. This is very necessary, because with perform reflection action will be able to know the constraints encountered when executing the action. This procedure will be repeated over and over until the data were obtained showed the best results or have met the success criteria has been determined. The conclusion of this procedure is to draw conclusions. In accordance with the characteristics of the CAR, this study consisted of several cycles. The cycle is carried out repeatedly or continuously until get the best results. The purpose of carrying out multiple cycles is to ind the best course of action so that the problems found can be be overcome . Data collection in this study was carried out by observation methods, tests, and interviews. Observation method or observation method is a method which is very appropriate to be used to observe the actions and objects sed by the community. Observation methods researchers use to collect data about student and teacher activities during the teaching and learning process. The observation technique used is the passive participation observation technique. Observation Passive participation is an observation activity carried out by the researcher himself by attending the activity concerned, but the researcher does not interact with research subjects. Researchers also use blank paper as a tool for recording learning activities that may appear outside of the guide written. In other words, the researchers used the field notes to check effect of implementing learning scenarios. Examples of student activity observation guides and teacher attached The interview method is used to obtain data that is not observed at the time observation . In this case, interviewing techniques are needed to obtain data about the constraints experienced by students or teachers when implementing the action. This interview technique is also carried out to seek student responses to implementation of applied learning. With interviews will be obtained constraints obtained when implementing actions and student responses against learning. The interview technique used is an unstructured interview technique, that is, free. In this case the researcher did not use the existing interview guidelines structured systematically and completely for data collection, but guidelines the interview used is only an outline of the problem asked (Sugiyono, 2009: 320). The researcher asks if the answer is that obtained has not answered the problem in this study so that the data btained absolutely accurately. The method that researchers use to measure student success in the ability to understand educational values in short stories is a test method. Instrument that is used is a test. The test that is used as an instrument is a test made with adjust to the theme / topic being discussed. From the assessment guidelines on each aspect of understanding ability Educational values in short stories are said to be successful if individually from 40 people students get a minimum score of 72 (minimum value of completeness), if $75 \%$ of the number of students in the class scored at least 72 actions can be stopped. The criteria for implementing the CIRC learning model in improving abilities Understanding educational values is seen from four aspects, namely, (1) activity observation student learning , (2) student responses to the implemented learning, (3) tests the ability to understand educational values and (4) observation of steps learning by teachers. After the data was collected, the next step that the researchers took was analyze data or process data. The techniques used in analyzing data is a descriptive qualitative analysis technique and quantitative descriptive. Qualitative descriptive techniques are used to analyze data in a way interpret the data obtained using words. Data obtained from the results of observations and interviews were analyzed using descriptive techniques qualitative. Quantitative descriptive techniques are used to analyze data in a way interpret the data obtained using the numbers. Data regarding a student's response is not analyzed quantitatively, but qualitatively. Data on student response results is determined from data from observations and interviews. Data were obtained from the research skills of students to express their 
IJEMS: Indonesian Journal of Education and Mathematical Science

2020 Vol. 1, No. 3, pp. 11-18 ISSN(e): 2715-985x

DOI: https://doi.org/10.30596/ijems.v1i3.2602

(C) 2020 IJEMS@UMSU. All Rights Reserved

opinions, in the form of scores were analyzed using a quantitative descriptive technique. Processing of all data obtained is carried out after the action is complete implemented, in order to obtain a clear picture of deficiencies or excess of actions that have been implemented. In analyzing all research data, researchers used the method deductive thinking. "In deductive logic, drawing a conclusion starts from general statements leading to specific statements using reasoning or ratio (rational thinking) "(Wendra, 2007: 3).

\section{DISCUSSION}

The results of this study state that (1) learning to understand values educative in short stories by applying the CIRC learning model capable increasing learning activities in the form of learning interactions among citizens, (2) students give a positive response to the application of the CIRC learning model, (3) achievement of improvement and completeness of student learning outcomes in understanding values educative short stories with the application of the CIRC learning model (4) are available several steps of implementing the CIRC learning model to increase activity and the achievement of completeness of learning outcomes the ability to understand educational values in short stories. The first finding is based on data analysis in cycle I, student learning activities class XI SMA N 1 Sigunung during the implementation of the CIRC learning model takes place looks more active than when participating in learning without application of the CIRC learning model. This can be indicated by the average value student activities before participating in learning with the CIRC learning model, that is, classically reaching 3.42. But after implementing the learning model CIRC in learning cycle I changes. Average learning activities students classically reached 3,6. This means from before the action takes place until the first cycle action has increased by 0.18 . The application of the CIRC learning model in learning to understand values in short stories, the students turned out to foster a positive response from students to lessons language Indonesia. Most of the students gave a positive response to actions taken in learning. In the first cycle, the average value of students' responses is 48 (positive). Furthermore, the increase in student learning outcomes until the level is reached completeness of student learning outcomes in the activities of understanding deep educational values short story class XI SMA N 1 Sigunung with the application of the model CIRC learning can be seen in the acquisition of test scores to understand educational values in the short stories of students in cycle I who experienced a lot of improvement and achieved KKM, namely 72. The steps taken by applying the CIRC learning model in improving the ability to understand educational values in short stories very effective in increasing students' understanding of literature. The steps taken by the teacher must be in accordance with the lesson plans made and include 8 components of the CIRC learning model, namely: (1) Teams, (2) Placement test, (3) Student creative, (4) Team study, (5) Team scorer and team recognition, (6) Teaching group, (7) Facts test, (8) Whole-class unit. Even though the learning carried out in cycle I seems to be sufficient good, but there are some obstacles that are still experienced by teachers and students when classroom learning takes place. These constraints are (1) teachers are not able to supervise students effectively so that cooperation in groups is lacking, (2) the teacher's test, the students felt was too difficult because their understanding was still lacking about short story analysis. This was because during group discussions, There is a lack of unidirectional understanding and cooperation in the discussions conducted less conducive, and (3) analysis conducted by students on every aspect those who are assessed in the test still need further explanation, (4) the teacher too not ready for the learning that has been done because the teacher is not yet too master the applied model. This is in line with Sutopo (2005: 143) who argued that one of the important components that must be mastered by the teacher in teaching are models and methods. Teaching is one component which must be mastered by the teacher as a manifestation of the 
IJEMS: Indonesian Journal of Education and Mathematical Science

2020 Vol. 1, No. 3, pp. 11-18 ISSN(e): 2715-985x

DOI: https://doi.org/10.30596/ijems.v1i3.2602

(C) 2020 IJEMS@UMSU. All Rights Reserved

competence of the teacher as an implementer front. The teacher is a very decisive component in an implementation learning strategy, especially in motivation and the ability to appreciate short story . Therefore students must have creativity in literary works. So that not critical in appreciating so as a student he must read a lot because reading will get a lot of knowledge. From the constraints experienced by teachers and students, the teacher too find a way out and overcome the problems experienced and that all done in planning the action in cycle II. On this planning, teacher starting with improving the way of teaching in the classroom, changing the classroom atmosphere so that it becomes more orderly and calm, improving the way students learn and provide opportunities for students to be more creative in groups by discussing openly and teaching students to be more courageous in asking questions regarding the problems experienced in the group. Furthermore, in cycle II data analysis, student learning activities in cycle II It can be observed from students' enthusiasm in learning activities when compared with cycle I. When students are given the opportunity to ask questions, students are very active. This matter This is indicated by the number of students who raised their hands and asked questions. Student orderliness has also been seen in the question and answer session of all students very active and enthusiastic about answering questions given by the teacher. There is even students who are enthusiastic about trying to answer questions even though they are not appointed by teacher. The application of the CIRC learning model in learning to understand values in the short stories, the students turned out to foster a very positive response from students towards Indonesian language lessons. Most of the students gave a positive response against the actions taken in learning. In the first cycle the average value student response was 49 (very positive). Students feel happy doing activities This learning is because it is applied with the CIRC learning model Increasing student learning outcomes until the level of completeness of the results is achieved student learning in the activities of understanding educational values in the short stories of class XI students SMAN 1 Sigunung with the application of the CIRC learning model is shown in the acquisition of test scores to understand the educational values in students' short stories in cycle I and II which has increased and achieved KKM, namely 72. At each stage learning scores of students always increase, both from the initial reflection, cycle I, and cycle II. The average score achieved by students in the initial reflection is 68 , the average score achieved by students in the first cycle was 77 , and the score in the cycle II is 90. The steps taken in applying the CIRC learning model in improving the ability to understand educational values in short stories very effective in increasing students' understanding of literature. The steps in cycle II are almost the same as the steps in cycle I, however the teacher emphasizes more in cycle II learning in groups with discussions done intensively through intensive question and answer than before. The second finding is theoretically, the CIRC type of cooperative learning model In general, it can be understood as learning that occurs in small groups where each student has the right to express their ideas and work together to complete the assigned task. Learning model cooperative type CIRC provides an opportunity to convey ideas or ideas, asking, discussing opinions with group members so reduce the heterogeneity of the group. Through activities carried out by students able to build or construct their own knowledge with the teacher as mediator and facilitator. The third finding, in line with Suyitno (2005), is the strength of the CIRC model learning appears active, creative and effective and fun, trains students to work in groups, practice harmony in living together basic mutual respect (life together). The advantages of the cooperative learning model type CIRC lies in the planning and construction of knowledge thus the teacher acts as an evaluator, facilitator and mediator. Teachers don't need to transfer all the knowledge to students to think and seek their own answers over the problems given by the teacher and students themselves through class discussions as well as group discussions based on their experiences that have been obtained from everyday life. The fourth 
IJEMS: Indonesian Journal of Education and Mathematical Science

2020 Vol. 1, No. 3, pp. 11-18 ISSN(e): 2715-985x

DOI: https://doi.org/10.30596/ijems.v1i3.2602

(C) 2020 IJEMS@UMSU. All Rights Reserved

finding, several advantages of the cooperative learning model type The CIRC is supported by several research results, namely Ega Kemalayanti (2011) conduct classroom action research on the influence of cooperative learning models type of CIRC towards physics learning outcomes. The results of his research indicate that the results student learning achieved using the CIRC model is different from that of students who learn to use conventional learning models. Descriptively, the group that studied using the CIRC model had higher means high compared to conventional learning. The implication of the research findings is learning to understand educational values in short stories by using the CIRC model can be improve optimal learning outcomes if the implementation of learning is based in the cooperative model, which is one of the learning models in which the activities are carried out teaching and learning between the concepts learned is associated with its application so will provide considerable opportunities in the language learning process Indonesia, especially literature that is more meaningful and students will build own knowledge through an active process in based learning the initial knowledge that students have. In addition, the CIRC learning model is not only concerned with individual student activities, but also contribution to group members so as to optimize cooperation between group members. Thing This can train students to be more responsible for the assigned task in his group. The CIRC learning model can be seeded in order improve student learning outcomes in literature. This is also supported by students' positive responses to the learning carried out. In other words classroom action research that was implemented was successful.

\section{CONCLUSION}

Based on the results of the research and discussion that has been presented in Chapter IV, conclusions can be drawn as follows. Class XI student learning activities of SMA $\mathrm{N} 1$ SIGUNUNG during implementation the CIRC learning model took place looked more active than when participating in learning without the application of the CIRC learning model. This can be shown, that the average value of student activities before participating in learning with the model CIRC learning, which is classically 3.42. However after implementation CIRC learning model in learning cycle I changes. The average student learning activities classically reached 3,6. This means from before holding the action until the first cycle of action has increased by 0.18 . In the second cycle the average student learning activities also increased by 1,2 so that becomes 4,8. Differences in student learning activities in cycle II can be observed from student enthusiasm in learning activities when compared to cycle I. When students are given the opportunity to ask questions, students are very active. This is indicated of the many students who raised their hands and asked. Student order too already seen in the question and answer session all the students seemed very active and enthusiastic answer questions given by the teacher. There are even students who are enthusiastic about it tries to answer the question even though the teacher doesn't point it. In this second cycle, students also pay more serious attention to the teacher's explanation when compared to cycle I. The application of the CIRC learning model in learning to understand inner values Students' short stories turned out to foster positive responses from students to language lessons Indonesia. Most of the students gave a positive response to action that is done in learning. In the first cycle, the average value of the students' responses was 48 (positive), then the average value of the student responses increased to 49 (very positive ) in cycle II. Students feel happy doing this learning activity because it is applied with the CIRC learning model. Increasing student learning outcomes to achieve the level of completeness of learning outcomes students in the activity of understanding educational values in short stories for class XI students SMA N 1 Sigunung with the application of the CIRC learning model is shown in the acquisition of short story comprehension test scores of students in cycles I and II who 
IJEMS: Indonesian Journal of Education and Mathematical Science

2020 Vol. 1, No. 3, pp. 11-18 ISSN(e): 2715-985x

DOI: https://doi.org/10.30596/ijems.v1i3.2602

(C) 2020 IJEMS@UMSU. All Rights Reserved

experienced improvement and achieving KKM, namely 72. At each stage of learning student scores always increasing, both from the initial reflection, cycle I, and cycle II. Acquisition the mean score that the students achieved on initial reflection was 68 , the mean score that was achieved by students in cycle I was 77, and the acquisition of scores in cycle II was 90 . On cycle I, the level of student mastery of short stories on aspects of religious value $80 \%$, value moral $84 \%$, social value $80 \%$, and cultural value $68 \%$. In cycle II, the level of mastery students towards these four aspects have increased, namely in the aspect of value religious values $92 \%$, moral values $92 \%$, social values $88 \%$, and cultural values $88 \%$ The steps taken in applying the CIRC deep learning model improve the ability to understand educational values in short stories effective in increasing students' understanding of literature. There are 8 components learning steps in the CIRC learning model; (1) Teaching Group, (2) Teams, (3) Student Creative, (4) Teams Study, (5) Teams Scorer and Team Recognition, (6 ) Whole Class Unite, (7) Task, (8) Placement Test.

\section{E. REFERENCES}

National Education Standards Agency. 2006. Guidelines for Level Curriculum Development Elementary and Secondary Education Unit.

Ministry of National Education. 2003. Big Indonesian Dictionary . Jakarta: Balai Pustaka.

Ega Kemalayanti, Ni Putu. 2011. "The Influence of Type Cooperative Learning Model CIRC Against Physics Learning Outcomes of High School Students for the 2010/2011 Academic Year. Thesis (unpublished). Department of Physics Education. Undiksha.

Sugiyono. 2009. Understanding Qualitative Research. Bandung: Alfabeta.

Suyitno, Amen. 2005. Adopting CIRC Learning to Improve Student Skills in Finishing Story uestions. F.MIPA National Seminar UNNES

Wendra, I Wayan. 2009. Writing Scientific Papers. Textbooks. Singaraja: UNDIKSHA 